\title{
Characterization of Pisolithus orientalis in culture and in vitro mycorrhization with Eucalyptus camaldulensis and Pinus kesiya
}

\author{
Kumla J, Suwannarach $\mathbf{N}$ and Lumyong S \\ Department of Biology, Faculty of Science, Chiang Mai University, 50200, Thailand
}

Kumla J, Suwannarach N, Lumyong S 2016 - Characterization of Pisolithus orientalis in culture and in vitro mycorrhization with Eucalyptus camaldulensis and Pinus kesiya. Mycosphere 7 (9), 1414-1424, Doi 10.5943/mycosphere/7/9/14

\begin{abstract}
A basidiome of Pisolithus orientalis was collected from northern Thailand and a pure culture was isolated. This study aimed to investigate the suitable mycelial growth conditions of this fungus and its ability to form ectomycorrhizal symbiosis with seedlings of Eucalyptus camaldulensis and Pinus kesiya in vitro. The fungal mycelium grew well on Murashige and Skoog medium that was adjusted to $\mathrm{pH} 5.0$ at $30{ }^{\circ} \mathrm{C}$. The plant seedlings were inoculated with fungal mycelium. The mycorrhization was first observed on pine and eucalyptus at 10 and 12 weeks after inoculation, respectively. Moreover, the identification of mycorrhizal association was confirmed by molecular methods. This is the first report of pure culture synthesis of Pis. orientalis mycorrhizae and the compatible of mycorrhizal formation of E. camaldulensis.
\end{abstract}

Key words - Ectomycorrhizal fungus - mycelial growth - mycorrhizal synthesis

\section{Introduction}

Ectomycorrhizal fungi can form a mutualistic relationship with roots, and these modified roots enhance nutrient and water uptake, increase tolerance to environmental stresses, promote plant growth and protect against pathogens (Brundrett et al. 1996, Chung et al. 2002, Brundrett 2004). Over 20,000 potential ectomycorrhizal species have been described to date (Taylor \& Alexander 2005). Many ectomycorrhizal fungal genera such as Amanita, Astraeus, Boletus, Hebeloma, Lactarius, Rhizopogon, Pisolithus, Scleroderma and Tricholoma can be cultivated in pure culture and most culturable ectomycorrhizal fungi rely on specific requirements. Therefore, many studies have attempted to define the optimal physical conditions and the suitable medium for their growth (Brundrett et al. 1996, Sanchez et al. 2001, Daza et al. 2006, Xu et al. 2008, Siri-in et al. 2014). Moreover, the mycorrhization ability of culturable ectomycorrhizal fungi was assessed by the re-inoculation of spores or mycelia to plant seedlings in the field or in the laboratory (Brundrett et al. 2004, Costa et al. 2010, Sanmee et al. 2010, Díez \& Horumbia 2011, Isiam \& Ohga 2013).

Pisolithus is a well-known ectomycorrhizal gasteroid fungus that belongs to the suborder Sclerodermatineae, order Boletales (Binder \& Hibbett 2006, Wilson et al. 2011). It is widespread in temperate and tropical regions and forms ectomycorrhiza with a broad range of woody plants including members of the families Cistaceae, Dipterocarpaceae, Fagaceae, Mimosaceae, Myrtaceae and Pinaceae (Marx 1977, Chambers \& Cairney 1999, Martin et al. 2002). The Pisolithus species have been used to increase the growth of tree seedlings, both in nurseries and in the field, especially 
in the inoculation programs of Eucalyptus spp. and Pinus spp. (Chamber \& Cairney 1999, Dell et al. 2002, Turjaman et al. 2005). Only three species of Pisolithus have been reported from Thailand. Pisolithus abditus colonizes Shorea roxburgii G. Don (Dipterocarpaceae) and Dipterocarpus alatus Roxb. (Dipterocarpaceae), while Pis. albus colonizes Eucalyptus camaldulensis Dehnh (Myrtaceae), and Pis. orientalis colonizes Pinus kesiya Royle ex Gordon (Pinaceae) (Kanchanaprayudh et al. 2003a, 2003b, Phosri et al. 2012). However, the authors of those studies only reported on field observations and did not describe the cultivation and mycorrhiza features of Pis. orientalis. This study aimed to investigate the optimum in vitro culture conditions for Pis. orientalis mycelial growth and to evaluate its ability to form ectomycorrhiza with E. camaldulensis and Pin. kesiya in vitro. Moreover, the ectomycorrhizal associations were described and confirmed by molecular techniques.

\section{Materials \& Methods}

\section{Fungal collection and pure culture isolation}

A basidiome of Pis. orientalis (SDBR-CMU53-6) was collected under Pin. kesiya in the Medicinal Plant Garden (1848'24.1"N, 98 54'51.1"E, elevation 1072 m), Doi Suthep-Pui National Park, Chiang Mai Province, Thailand in June, 2014. The mycelium was then isolated from basidiome by aseptically removing small pieces of tissue from the inside of basidiome, transferring it to modified Melin-Norkans (MMN) medium (Langer et al. 2008). Pure culture was deposited in the Culture Collection of Research Laboratory for Excellence in Sustainable Development of Biological Resources, Faculty of Science, Chiang Mai University, Thailand as ID number SDBRCMU53-P6.

\section{Mycelial growth tests}

Twenty-five milliliters of culture medium for each experiment were poured into Petri-dishes (9 $\mathrm{cm}$ diameter) after autoclaving for $15 \mathrm{~min}$ at $121{ }^{\circ} \mathrm{C}$. A sterilized cellophane disc $(9 \mathrm{~cm}$ diameter) was placed on the surface of the tested media following the method described by De Araújo \& Roussos (2002). A mycelial plug (5 mm diameter) was obtained from two week-old culture at $30{ }^{\circ} \mathrm{C}$ on MMN medium and transferred to the tested media. The inoculated plates were sealed with Parafilm and incubated. After three weeks of inoculation, the colony diameter was measured and mycelial dry weight was obtained after the slides were dried at $60{ }^{\circ} \mathrm{C}$ overnight and maintained in desiccators for $30 \mathrm{~min}$. Each treatment was performed in five replicates.

Effect of cultivation medium - The following ten different media were tested for the mycelial growth of Pis. orientalis; ammonium chloride glucose agar (AGC; Xu et al. 2008), fungalhost agar (FH; Vaario et al. 2000), Heli medium (HI; Xu et al. 2008), Hagem's medium (HG; McLaughlin 1970), MMN medium (Langer et al. 2008), G-MMN medium (Gafur et al. 2004), LMMN medium (Langer et al. 2008), Murashige and Skoog medium (MS; Danell 1994), malt extract agar (MEA; Sanmee et al. 2010), and SH medium (Guerin-Laguette et al. 2000). All tested media were adjusted to $\mathrm{pH} 6.0$ with $1 \mathrm{~N} \mathrm{HCl}$ or $1 \mathrm{~N} \mathrm{NaOH}$ before autoclaving. The inoculated plates were incubated at $30{ }^{\circ} \mathrm{C}$ in darkness for three weeks. The medium that presented the largest colony diameter and highest biomass yield was selected for further experiments.

Effect of temperature - In this experiment, pure culture of Pis. orientalis was inculcated in the selected medium that had been obtained from previous experiments. The media was adjusted to pH 6.0 before autoclaving. The inoculated plates were incubated in darkness at 15, 20, 25, 30, 35, 40 and $45{ }^{\circ} \mathrm{C}$. After three weeks of inoculation, colony diameters and dry weights were measured. The temperature that presented the largest colony diameter and highest biomass yield was selected for further experiments.

Effect of initial $\mathrm{pH}$ value of medium - Pure culture of Pis. orientalis was inoculated on selected medium with initial $\mathrm{pH}$ values ranging from 3.0-9.0 before autoclaving. The colony diameter and dry weights were measured after three weeks of incubation in the darkness at the suitable temperature for mycelial growth that was obtained from the previous experiment. 


\section{In vitro mycorrhizal synthesis}

Plant material - Two tree species, E. camaldulensis and Pin. kesiya were used in this study. Plant seeds were obtained from the experimental orchard of the Department of Biology, Faculty of Science, Chiang Mai University and kept at $4{ }^{\circ} \mathrm{C}$ until being used. Both types of seeds were surface sterilized by soaking in $1 \% \mathrm{H}_{2} \mathrm{O}_{2}$ for 5 days at $5{ }^{\circ} \mathrm{C}$, rinsed in sterile water, soaked in $30 \% \mathrm{H}_{2} \mathrm{O}_{2}$ for about $35 \mathrm{~min}$, and finally washed three times with sterile water for 5-10 min. The sterilized seeds were planted on Petri dishes $(14.0 \mathrm{~cm}$ diameter) which contained $100 \mathrm{ml}$ of $1.0 \%$ water agar at a $\mathrm{pH}$ of 6.0 and the planted plates were incubated in a growth chamber at $25 \pm 2{ }^{\circ} \mathrm{C}, 70 \pm 10 \% \mathrm{RH}$ and then illuminated for $12 \mathrm{~h}$ with fluorescent lamps at about $1500 \mathrm{~lx}$. Seeds of both plant species germinated in $7-15$ days.

Fungal inoculum preparation - The inoculum was prepared by the modified method of Lee et al. (2008). The $25 \mathrm{ml}$ of a peat:vermiculite mixture (1:9, v/v) was placed in $200 \mathrm{ml}$ glass bottles, $15 \mathrm{ml}$ of MS liquid medium (pH 5.0) was added and the glass bottles were autoclaved at $121{ }^{\circ} \mathrm{C}$ for $30 \mathrm{~min}$. After cooling, three mycelial plugs from the periphery of the growing colony on MS medium were then transferred to glass bottles and incubated at $30{ }^{\circ} \mathrm{C}$ in the darkness. After 30 days of incubation, the fungal mycelium completely covered the surface and was used as an inoculum.

Mycorrhizal synthesis - Fungal inocula were leached three times with sterile distilled water to remove excess sugars and nutrients before being used. Three seedlings of 15 day-old of eucalyptus and pine were transferred onto the surface of the fungal inoculum. There were ten replicated glass bottles per each plant species. The inoculated glass bottles were maintained in a growth chamber, for which the conditions were explained above.

Morphological characterization of synthesized ectomycorrhizae - Fungal colonization was investigated every week after inoculation. The plant roots of each plant were sampled to assess mycorrhizal development under a stereomicroscope (Olympus TL3, Japan). Morphological characteristics of ten fungal-colonized roots were examined under a light microscope (Olympus CX51, Japan) following Agerer $(1991,2006)$. The presence of an ECM mantle and Hartig net was assessed on handmade sections of root tips mounted in $3 \% \mathrm{KOH}$ or $1 \%$ Congo red. The fungus colonized roots were washed three times with sterilized water for molecular analysis.

Molecular analysis of synthesized ectomycorrhizae - Genomic DNA was extracted from single fungus-colonized root tips of each plant as described by Paolocci et al. (1999) and pure culture (1-10 mg) using the Nucleospin Plant II (Macherey-Nagel, Germany) according to the manufacturers' protocols. The internal transcribed spacer (ITS) region of ribosomal DNA was amplified by PCR using ITS1F and ITS4 primers (White et al. 1990) under the following thermal conditions: $95{ }^{\circ} \mathrm{C}$ for $2 \mathrm{~min}, 30$ cycles of $95{ }^{\circ} \mathrm{C}$ for $30 \mathrm{~s}, 50{ }^{\circ} \mathrm{C}$ for $30 \mathrm{~s}, 72{ }^{\circ} \mathrm{C}$ for $1 \mathrm{~min}$, and $72{ }^{\circ} \mathrm{C}$ for $10 \mathrm{~min}$ on a GeneAmp 9700 thermal cycler (Applied Biosystems, USA). PCR products were checked on $1 \%$ agarose gels stained with ethidium bromide under UV light. PCR products were purified using a PCR clean up Gel Extraction NucleoSpin ${ }^{\circledR}$ Gel and PCR Clean-up Kit (MachereyNagel, Germany) following the manufacturer's protocol. The purified PCR products were directly sequenced. Sequencing reactions were performed and the sequences were automatically determined in the genetic analyzer at $1^{\text {ST }}$ Base company (Kembangan, Malaysia) using the PCR primers mentioned above. Sequences were used to query GenBank via BLAST (http://blast.ddbj.nig.ac.jp/ top-e.html). For phylogenetic analysis, the sequences of a pure fungus and fungal symbionts were obtained in this study and from GenBank. The multiple sequence alignment was carried out using MUSCLE (Edgar 2004), and ITS alignments were deposited in TreeBASE under number 15567. A phylogenetic trees were constructed using PAUP* 4.0b10 (Swofford 2002). In maximum parsimony analysis, all characters were equally weighted and gaps were treated as missing data. Heuristic searches with 100 random-addition sequence replicates and tree-bisection-reconnection branch swapping were performed. Bootstrap analysis (Felsenstein 1985) was conducted with 1000 replicates. The parsimony tree scores, including tree length and consistency, retention, rescaled consistency, and homoplasy indices (CI, RI, RC, and HI), were calculated. Bayensian phylogenetic analyses were carried out using the Metropolis coupled Markov chain Monte Carlo (MCMCMC) method with MrBayes v3.2 (Ronquist et al. 2012), under a GRT+I+G model. Markov chains were 
run for 1,000,000 generations, with six chains and random starting trees. The chains were sampled every 100 generations. Among these, the first 2000 trees were discarded as the burn-in phase of each analysis and the resulting trees were used to calculate Bayesian posterior probabilities.

\section{Statistical analysis}

Data were analyzed by one-way analysis of variance (ANOVA) by SPSS program version 16.0 for Windows and Tukey's test was used for significant differences $(P<0.05)$ between treatments.

\section{Results}

\section{Effect of cultivation media on mycelial growth}

Pure culture of Pis. orientalis consisted of yellow-brown velvety mycelia, $1.25-3 \mu \mathrm{m}$ in diameter, septate hyphae with clamp connections and produced a yellowish to reddish dark-brown pigment that was diffused throughout the media. After three weeks of incubation, the amounts of radial mycelial growth and dried biomass yields of Pis. orientalis were affected significantly by the growth media. The largest colony diameter was obtained on MS medium $(89.83 \pm 0.29 \mathrm{~mm})$, followed by MMN medium $(73.73 \pm 3.51 \mathrm{~mm})$, G-MMN medium $(65.50 \pm 1.71 \mathrm{~mm})$ and L-MMN medium $(62.00 \pm 1.30 \mathrm{~mm})$ (Fig. 1A). The highest dried biomass yield was obtained from MS medium $\left(95.75 \pm 2.76 \mathrm{mg}\right.$ plate $\left.^{-1}\right)$. Whereas, the smallest colony diameter $(21.60 \pm 1.65 \mathrm{~mm})$ and the lowest dried biomass yield $\left(19.06 \pm 2.03 \mathrm{mg} \mathrm{plate}^{-1}\right)$ were obtained on SH medium.

\section{Effect of temperature and initial pH value of medium on mycelial growth}

Under the tested temperatures, a fungus could grow at temperatures ranging from 15 to 35 ${ }^{\circ} \mathrm{C}$ (Fig. 1B). The statistical analysis of the data showed that the mycelia of Pis. orientalis had the largest colony diameter $(89.73 \pm 0.25 \mathrm{~mm})$ and highest dried biomass yield $\left(98.53 \pm 1.96 \mathrm{mg} \mathrm{plate}^{-1}\right)$ on MS medium at $30{ }^{\circ} \mathrm{C}$. However, a fungus could not grow at temperatures at 40 and $45^{\circ} \mathrm{C}$ after three weeks of incubation.

Our results indicate that the initial $\mathrm{pH}$ medium affected the fungal growth (Fig. 1C). The mycelia of Pis. orientalis had the ability to grow at a tested $\mathrm{pH}$ value ranges of 3.0 to 9.0. The significantly largest colony diameter $(89.50 \pm 0.50 \mathrm{~mm})$ and biomass yield $\left(125.68 \pm 3.10 \mathrm{mg}\right.$ plate $\left.^{-1}\right)$ were found in MS medium at $\mathrm{pH}$ 5.0. It was found that the smallest colony diameter and biomass yield were observed at $\mathrm{pH} 9.0$.

\section{In vitro mycorrhizal synthesis}

The ITS sequence of a pure culture sequence of this fungus was deposited at GenBank under accession number JQ365188. Under the mycorrhizal synthesis conditions, ectomycorrhizal tips were first observed on Pin. kesiya and E. camaldulensis and at 10 and 12 weeks after inoculation, respectively. No ectomycorrhizal formation was observed in the un-inoculated control of both plants. Two ITS sequences of the fungal symbiont of pine and eucalyptus mycorrhizae were obtained and deposited under accession number KJ490637 and KJ490638, respectively. For the phylogenetic analysis, the aligned data set of these 24 sequences consisted of 753 characters, of which 371 characters were constant, 74 variable characters were parsimony uninformative, and 308 characters were parsimony informative. Heuristic searches resulted in a tree length of 726 steps, $\mathrm{CI}=0.792, \mathrm{RI}=0.870, \mathrm{RC}=0.689$ and $\mathrm{HI}=0.208$. One of 47 maximum-parsimony tree is shown in Fig. 2. A phylogram confirmed that the fungal symbiont of the selected mycorrhizae was in the same clade of the Pis. orientalis and both sequences had the $100 \%$ similarity with Pis. orientalis pure culture. Therefore, the fungal symbiont was Pis. orientalis.

The mycorrhizal root systems of Pin. kesiya were found to be forked and dichotomously branched. The branched ends were straight to somewhat slightly curved, $2.5-5.00 \mathrm{~mm}$ in length and 0.3-0.6 $\mathrm{mm}$ in diameter (Fig. 3A). The emanating hyphae connected to the fungal mantle sheath were straight, $1.50-3.50 \mu \mathrm{m}$ in diameter and with clamp connections. Cystidia were absent. 


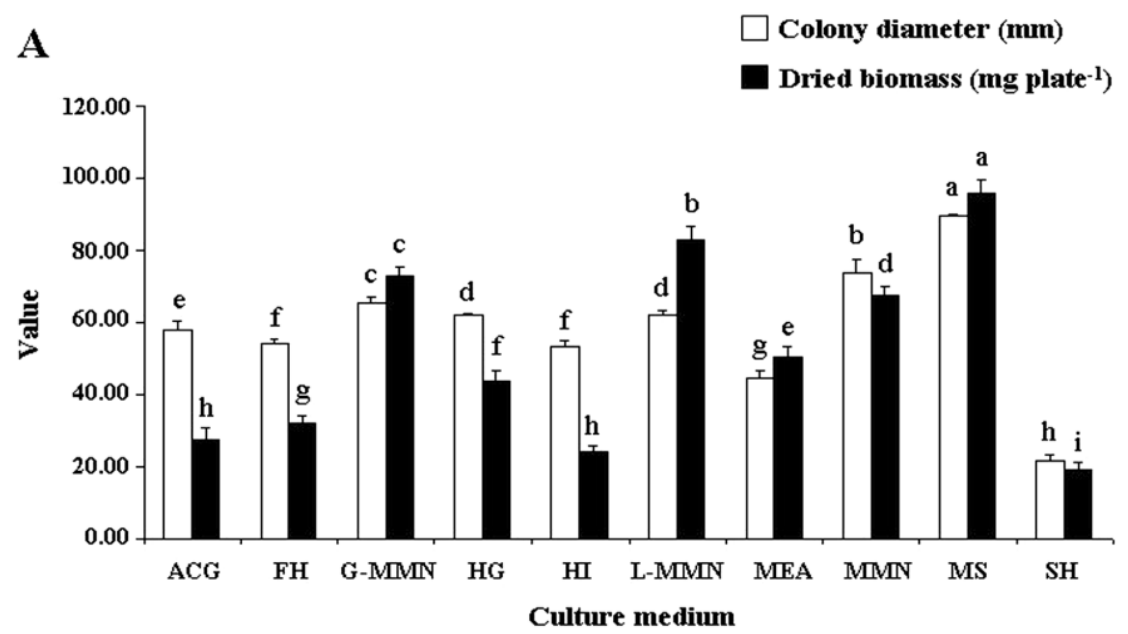

B

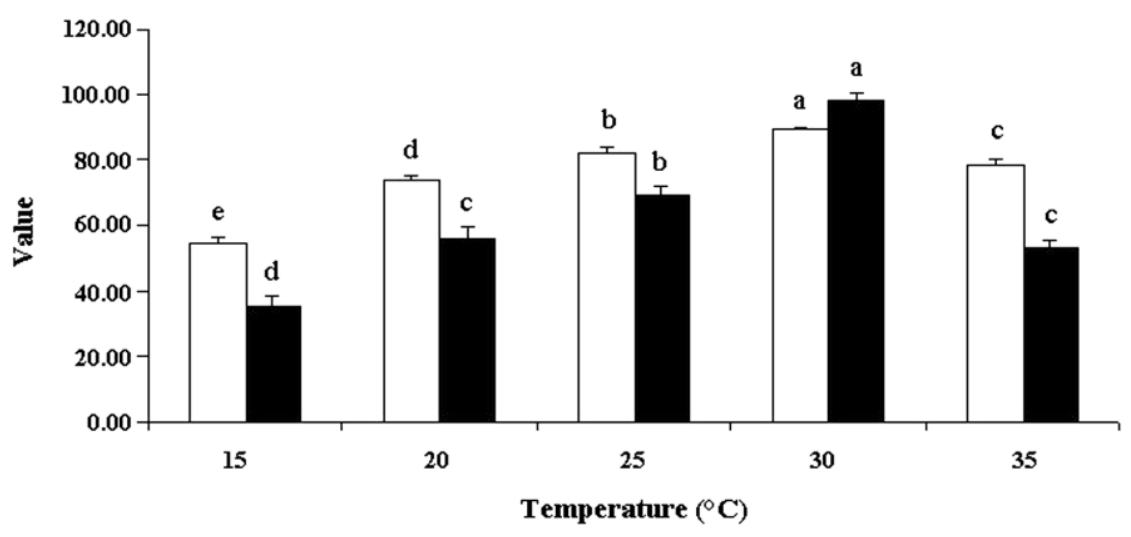

C

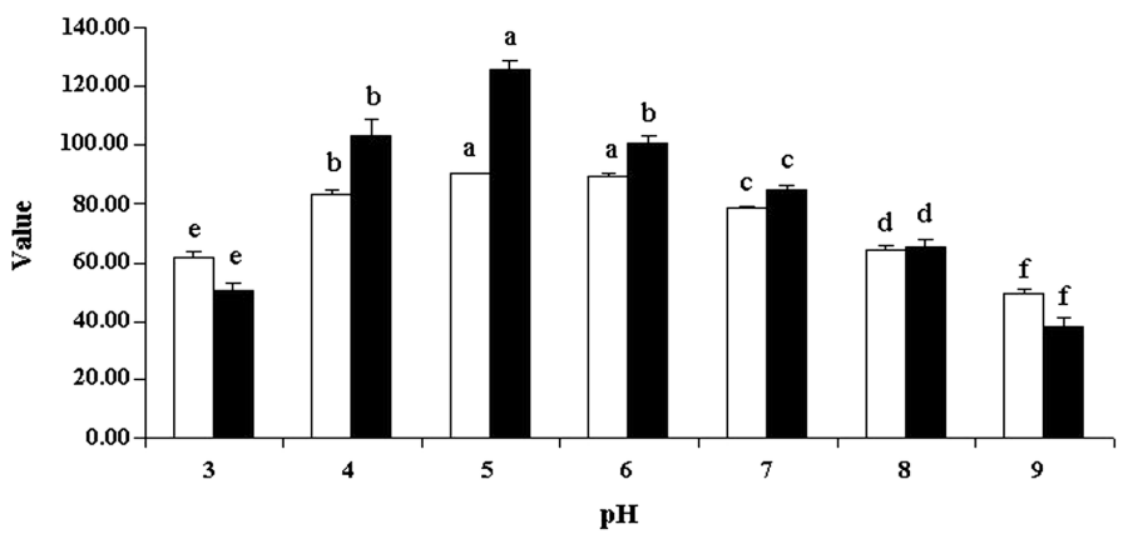

Fig. 1 - Cultivation of Pisolithus orientais SDBR-CMU53-P6. A: Effect of culture media on mycelail growth. B: Effect of temperature on mycelail growth. C: Effect of $\mathrm{pH}$ on mycelial growth. Data were means of five replicates. Error bar at each point indicated that $+\mathrm{SD}$. Different letters above each graph indicated the significant difference $(P<$ 0.05). $\mathrm{ACG}=$ ammonium choloride glucose agar, $\mathrm{FH}=$ fungal-host agar, $\mathrm{G}-\mathrm{MMN}=\mathrm{G}-\mathrm{MMN}$ medium, $\mathrm{HG}=$ Hagem's medium, $\mathrm{HI}=$ Heli medium, $\mathrm{MMN}=\mathrm{L}-\mathrm{MMN}$ medium, MEA = malt extract agar, MMN = modified Melin-Norkans medium, $\mathrm{MS}=$ Murashige and Skoog medium and $\mathrm{SH}=\mathrm{SH}$ medium.

Outer and inner layers were plectenchymatous as B type after Agerer's (2006) categorization, consisting of hyphae 3.5-12.0 $\mu \mathrm{m}$ in diameter, were arranged net-like and were repeatedly and squarrosely branched (Fig. 3B). A cross section of the mycorrhizal root showed a 10-15 $\mu \mathrm{m}$-thick mantle arranged in four to six cell layers. A Hartig net developed continuously at the cortex of the roots. The hyphae appeared with palmetti structure (Fig. 3C). 


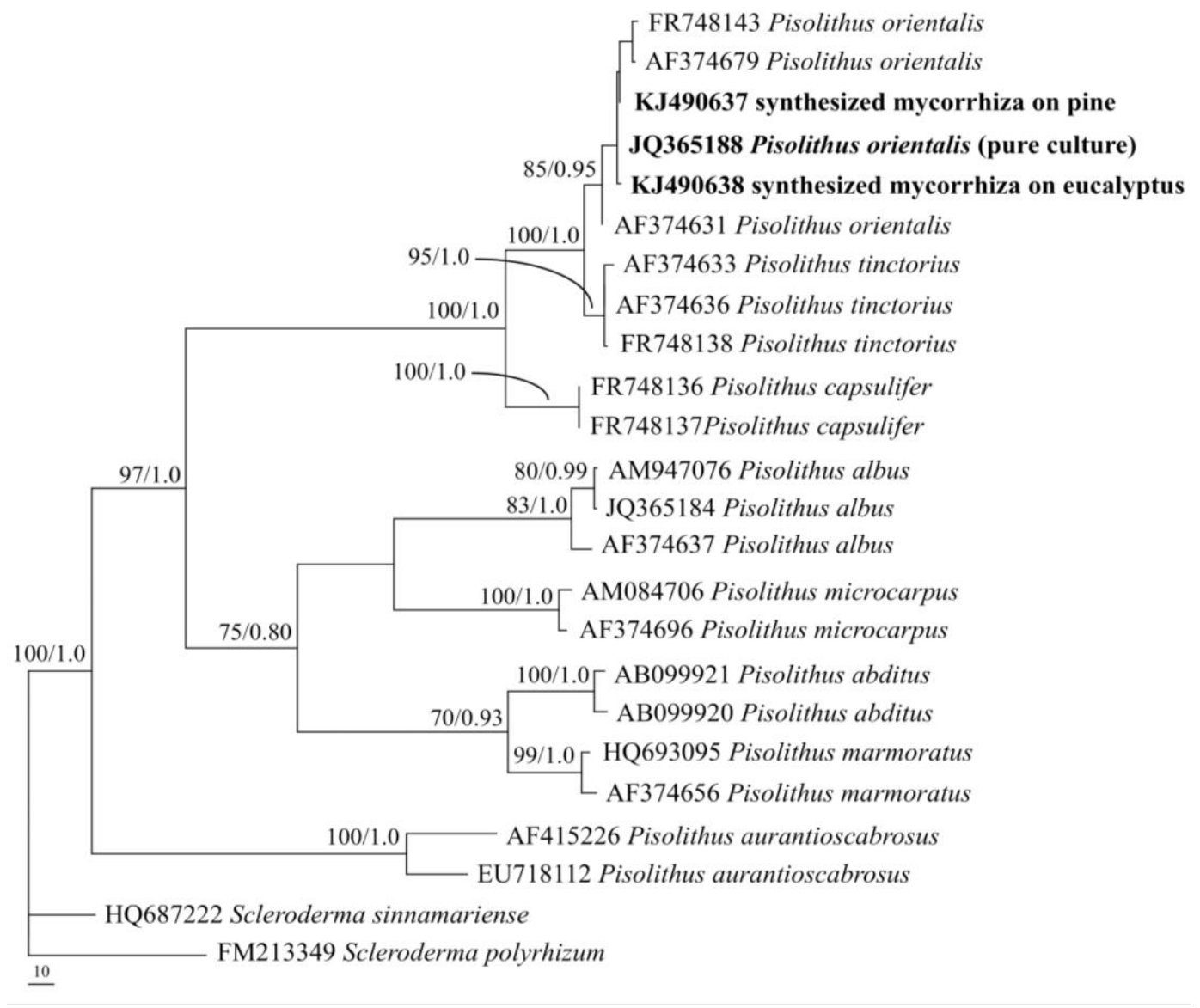

Fig. 2 - Maximum-parsimonious trees inferred from a heuristic search of ITS region of rDNA of 24 sequences. Scleroderma polyrhizum and Scl. sinnamariense were used as the outgroup. Numbers above branches identify the bootstrap statistics percentages (left) and Bayesian posterior probabilities (right). Branches with bootstrap values $\geq 50$ $\%$ are shown at each branch and the bar represents ten shown substitutions per nucleotide position. The sequences in this study are in bold.
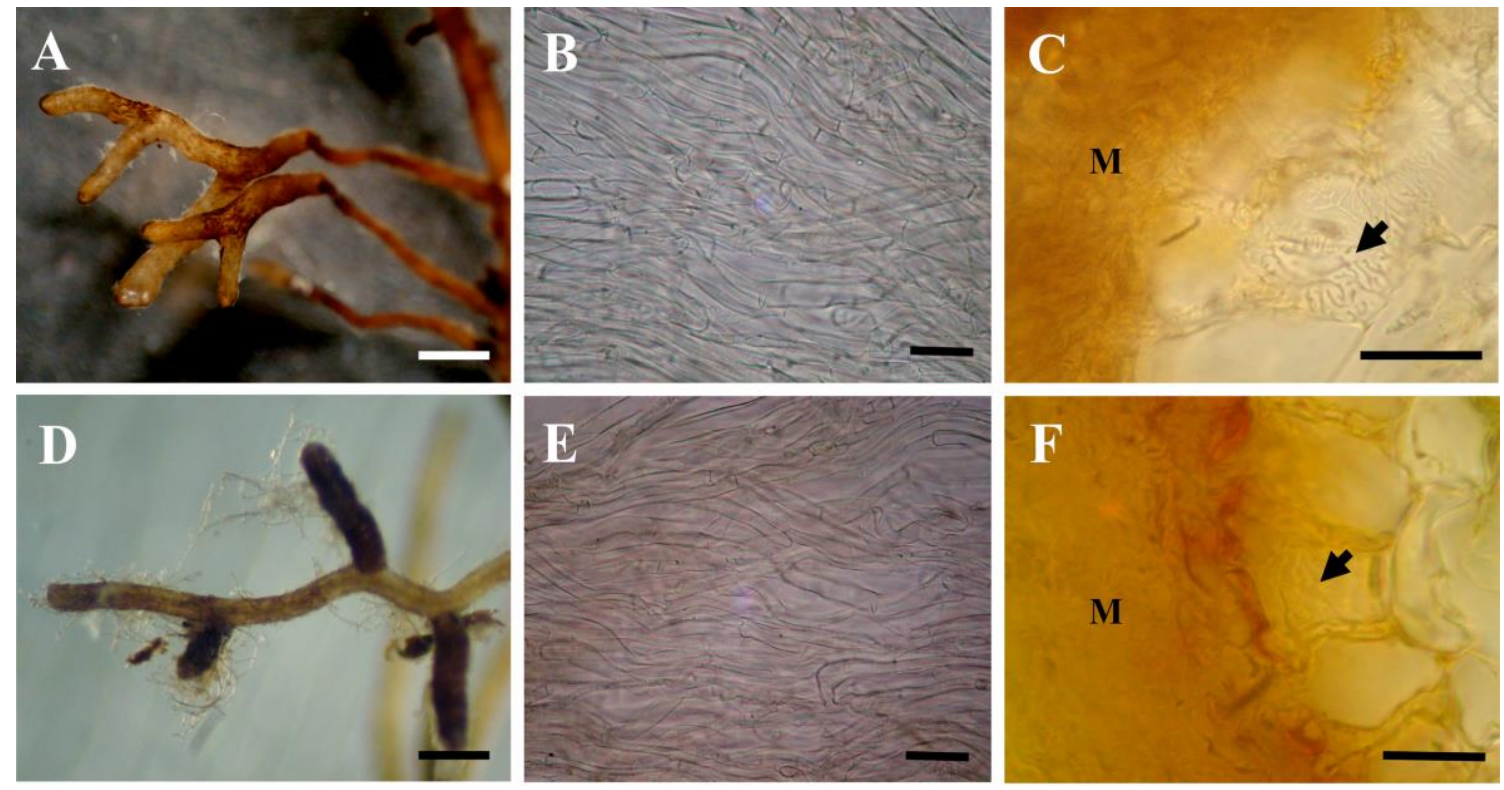

Fig. 3 - In vitro mycorrhization of Pisolithus orientalis SDBR-CMU53-P6. A: Mycorrhizal root tips of Pinus kesiya. B: The outer mantle layer. C: Cross section of mycorrhizal root tips of Pin. kesiya showed mantle sheath (M) and Hartig net (arrowed). D: Mycorrhizal root tips of Eucalyptus camaldulensis. E: The outer mantle layer. F: Cross section of mycorrhizal root tips of E. camaldulensis showed mantle sheath (M) and Hartig net (arrowed). Bars: A, C = $1 \mathrm{~mm}$; $\mathrm{B}, \mathrm{D}=5 \mu \mathrm{m} ; \mathrm{C}, \mathrm{F}=20 \mu \mathrm{m}$. 
The mycorrhizal root systems of E. camaldulensis were monopodial-pinnate to pyramidal pinnate in the basal part, 2.5-5.00 $\mathrm{mm}$ in length and $0.4-0.8 \mathrm{~mm}$ in diameter (Fig. 3D). The emanating hyphae connected to the fungal mantle sheath were straight, $1.2-3.5 \mu \mathrm{m}$ in diameter and with clamp connections. Cystidia were absent. Outer and inner layers were plectenchymatous as B type, consisted of hyphae of 3.5-15.0 $\mu \mathrm{m}$ in diameter, were arranged net-like, and were repeatedly and squarrosely branched (Fig. 3E). A cross section of the mycorrhizal root showed a 10-16.5 $\mu \mathrm{m}-$ thick mantle arranged in three to six cell layers. A Hartig net penetrated up to the epidermal cells and appeared with a palmetti structure (Fig. 3F). The hyphae did not exceed the cortex layer.

\section{Discussion}

The present study determined the suitable conditions for the mycelial growth of Pis. orientalis and its in vitro mycorrhization ability. Our study showed that the mycelial growth of Pis. orientalis was varied in different cultivation media, for which MS medium exhibited both the largest fungal colony diameter and biomass production. This result was supported by the findings of the several previous studies that reported that the mycelial growth of ectomycorrhizal fungi in pure cultures is greatly influenced by changes in the cultivation medium (Brundrett et al. 1996, Xu et al. 2008, Sanmee et al. 2010, Rossi \& Oliveira 2011). Moreover, the suitable cultivation medium for the mycelial growth of ectomycorrhizal fungi was dependent upon the ectomycorrhizal fungi species. For example, MS medium was determined to be the suitable medium for the mycelial growth of Phlebopus portentosus (Sanmee et al. 2010; Thongklang et al. 2010; Kumla et al. 2011), whereas Scleroderma sinnamariense grew well on FH medium (Siri-in et al. 2014). Xu et al. (2008) found that the pure culture of Lactarius insulsus and Boletus edulis grew best on potato juice ironmagnesium agar, but Lac. deliciosus grew best on the pine juice iron-magnesium agar. Islam \& Ohga (2013) reported that Rhizopogon roseolus and Tricholoma matsutake pure cultures grew best on PDA, while PGK medium was found to be a suitable medium for the mycelial growth of Pis. microcarpus (Rossi \& Oliveira 2011).

The temperature and $\mathrm{pH}$ value had a significant effect on the mycelial growth of Pis. orientalis. This fungus was able to grow at temperatures ranging from 15 to $35{ }^{\circ} \mathrm{C}$, with $30{ }^{\circ} \mathrm{C}$ proved to be the optimal temperature. These results were in accordance with the findings of previous studies that had reported that the optimal temperature for mycelial growth of most culturable ectomycorrhizal fungi ranged from 20 to $30{ }^{\circ} \mathrm{C}$ depending on the fungal species, as well as on the fungal isolate (Brundrett et al. 1996, Sanchez et al. 2001, Daza et al. 2006, Xu et al. 2008). Pisolithus tinctorius (Srinivasan et al. 2000), Phl. portentosus (Sanmee et al. 2010, Thongklang et al. 2010, Kumla et al. 2011) and Scl. sinnamariense (Siri-in et al. 2014) showed the largest biomass production at $30{ }^{\circ} \mathrm{C}$. Cantharellus cibarius, Lac. deliciosus, Lac. insulsus and Scl. bovista grew best at $25{ }^{\circ} \mathrm{C}$ (Xu et al. 2008, Yadav \& Yadav 2012), while $28{ }^{\circ} \mathrm{C}$ was the most suitable temperature for the mycelial growth of B. edulis (Xu et al. 2008). The $\mathrm{pH}$ value of the cultivation medium is one of the external factors that play a significant role in the mycelial growth of ectomycorrhizal fungi. Our results showed that Pis. orientalis had the ability to grow at $\mathrm{pH} 3.0$ 9.0, with an optimal $\mathrm{pH}$ of 5.0. This result agreed with those of several previous studies, which had reported that the mycelial growth of culturable ectomycorrhizal fungi generally favor acidic conditions (Dix \& Webstor 1995, Srinivasan et al. 2000, Yamanaka 2003). However, the optimum $\mathrm{pH}$ value of the medium for the mycelial growth of ectomycorrhizal fungi is not homologous for the fungal species and isolate. For example, studies involving Hebeloma vinosophyllum, Lac. deliciosus and Pis. tinctorius indicated that the optimum pH value was 6.0 (Srinivasan et al. 2000, Yamanaka 2003, Xu et al. 2008) and a pH value of 4.0 supported the growth of Phl. portentosus (Sanmee et al. 2010, Thongklang et al. 2010, Kumla et al. 2011). The pure cultures of Amanita caesarea had the largest radial growth at pH 6.0-7.0 depending on the isolates (Daza et al. 2006). The highest growth was obtained at a $\mathrm{pH}$ value of 5.0 for B. edulis, C. cibarius, R. roseolus, $T$. matsutake and Scl. sinnamariense (Xu et al. 2008, Yadav \& Yadav 2012, Islam \& Ohga 2013, Siriin et al. 2014). However, some ectomycorrhizal species favor neutral to slightly alkaline conditions such as H. edurum, Lac. insulsus and Suillus collinitus (Hung \& Trappe 1983, Xu et al. 2008). 
Based on prior field investigations, Pis. orientalis is generally associated with Pin. kesiya in Thailand (Phosri et al. 2012) and Martin et al. 2002 reported that it is associated with pines (Pin. elliotii Engel. and Pin. Yunnanensis Franch.) and eucalypts (E. maidenii F. Muell. and E. urophylla S. T. Blake) in China. However, the mychorrizal in these studies have been recorded without the inclusion of anatomical descriptions. Our results indicate that Pis. orientalis is able to form in vitro ectomycorrhizae on Pin. kesiya and E. camaldulensis, for which both of the mantle sheathes were plectenchymatous and similar to the mantle sheath of Pis. tinctorius with Abies firma Siebold \& Zucc (Pinaceae), Quercus ilex L. (Fagaceae) and Q. coccifera L. (Vaario et al. 1999, De Roman \& De Miguel 2005, Díez \& Honrubia 2011), Pis. microcarpus with E. grandis Hill ex Mainden (Costa et al. 2010) and Pis. aurantioscabrosus with Shorea sp. (Dipterocarpaceae) (Watling et al. 1995). However, variations in the mantle sheaths have been reported to depend on the species and isolates of Pisolithus. Additionally, the comparison of younger and older parts of the same mycorrhizal specimen revealed a certain amount of variable feature overlap (Burgess et al. 1994). Tam (1994) reported that the prosenchymatous-mantle (type A) was found on the in vitro mycorrhizal synthesis between Pis. tinctorius and pines (Pin. massoniana Lamb. and Pin. elliottii). Those observations suggest that the anatomical characteristics of mycorrhizas are not sufficient for the identification of the fungal symbiont species. Conversely, the molecular analyses have provided the researcher with powerful tools to identify the genetic differences between fungal symbiont species. Therefore, combining the molecular and anatomical approaches would appear to be most appropriate in identifying ectomycorrhizae (Garay-Serrano et al. 2012, Boutahir et al. 2013).

This study is the first report on the compatibility of ectomycorrhizal formation of Pis. orientalis and E. camaldulensis. The results of this study were supported by the findings of the study of Pereira et al. (2005) who reported that some Pisolithus isolates from pines could form ectomycorrhizae with a non-original host (eucalyptus) in green house experiment and could be indicative of the compatible mycorrhization. A pure culture of Pis. tinctorius had a compatible mycorrhizal association with Pin. taiwanensis Hayata in aseptic conditions, but this association had not been found with this plant in nature (Hung \& Chien 1979). Gomes et al. (2013) found that Pis. arhizus culture isolated from basidiome associated with $Q$. suber $\mathrm{L}$. had the ability to form compatible mycorrhiza with Arbutus unedo L. (Ericaceae) under laboratory and nursery trials. The compatible ectomycorrhizal formation is affected by plant species and the fungal isolates (Pereira et al. 2005, Pruett et al. 2009, Bahram et al. 2011). Moreover, previous studies have reported that the contrastive findings that exist between field observations and inoculation experiments may result from ecological specificity. The interactions of fungus and plant may be less constrained under culture conditions than in natural conditions because culture conditions could limit competition from indigenous fungi (Molina et al. 1982, Brundrett et al. 1996, Martin et al. 2002, Yamanaka et al. 2014).

In conclusion, this study provides valuable information for Pis. orientalis mycelium cultivation. Moreover, a fungus is able to form ectomycorrhiza with E. camaldulensis and Pin. kesiya. The ectomycorrhizae was confirmed by molecular analysis. The results of this study can be applied to help researchers select suitable conditions to support mycelial growth for mycelial inocula production in the application and management of plant inoculation programs in Thailand.

\section{Acknowledgements}

This work was supported by grants from Chiang Mai University and Thailand Research Fund (TRF) for The Research-Team Promotion Grant (RTA5880006). We are grateful to Russell Kirk Hollis for English proofreading.

\section{References}

Agerer R. 1991 - Characterization of ectomycorrhiza. In: Norris JR, Read DJ, Varma AK (eds), Methods in microbiology: techniques for the study of mycorrhiza. Academic Press, London, pp 25-73. 
Agerer R. 2006 - Fungal relationships and structural identity of their ectomycorrhizae. Mycological Progress 5, 67-107.

Bahram M, Põlme S, Kõljalg U, Tedersoo L. 2011 - A single European aspen (Populus tremula) tree individual may potentially harbour dozens of Cenococcum geophilum ITS genotypes and hundreds of species of ectomycorrhizal fungi. FEMS Microbiology Ecology 75, 313-320.

Binder M, Hibbett DS. 2006 - Molecular systematics and biological diversification of Boletales. Mycologia 98, 971-981.

Boutahir S, Iotti M, Piattoni F, Zambonelli A. 2013 - Morphological and molecular characterization of Tuber oligospermum mycorrhizas. African Journal of Agricultural Research 8, 4081-4087.

Brundrett M. 2004 - Diversity and classification of mycorrhizal association. Biological Reviews 79, 479-495.

Brundrett M, Bougher N, Dell B, Grove T, Malajczuk N. 1996 - Working with mycorrhizas in forestry and agriculture. ACIAR Monograph, Canberra.

Burgess T, Dell B, Malajczuk N. 1994 - Variation in mycorrhizal development and growth stimulation by 20 Pisolithus isolates inoculated onto Eucalyptus grandis W. Hill ex Maiden. New Phytologist 127, 731-739.

Chambers SM, Cairney JWG. 1999 - Pisolithus. In: Cairney JWG, Chambers SM (eds), Ectomycorrhizal fungi. Key genera in profile. Springer-Verlag, Berlin.

Chung HC, Kim DH, Lee SS. 2002 - Mycorrhizal formations and seedling growth of Pinus densiflora by in vitro synthesis with the inoculations of ectomycorrhizal fungi. Mycobiology 30, 70-75.

Costa MD, Campos ANR, Santos ML, Borges AC. 2010 - In vitro ectomycorrhiza formation by monokaryoic and dikaryotic isolates of Pisolithus microcarpus in Eucalyptus grandis. Revista Árvore 34, 377-387.

Danell E. 1994 - Cantharellus cibarius: mycorrhiza formation and ecology. PhD thesis, Uppsala University, Uppsala.

Daza A, Manjón JL. Camacho M, Romero de la Osa L, Aguilar A, Santamaría C. 2006 - Effect of carbon and nitrogen sources, $\mathrm{pH}$ and temperature on in vitro culture of several isolates of Amanita caesarea (Scop.:Fr.) Pers. Mycorrhiza 16, 133-136.

De Álvaro ÁA, Roussos S. 2002 - A techinique for mycelial development of ectomycorrhizal fungi on agar media. Applied Biochemistry and Biotechnology 98, 311-318.

De Roman M, De Miguel A. 2005 - Post-fire, seasonal and annual dynamics of the ectomycorrhizal community in a Quercus ilex L. forest over a 3-year period. Mycorrhiza 15, 471-482.

Dell B, Malajczuk N, Dunstan WA. 2002 - Persistence of some Australian Pisolithus species introduced into eucalyptus plantations in China. Forest Ecology Management 169, 271-281.

Díez J, Horumbia M. 2011 - New report of the mycorrhizal association between Pisolithus tinctorius (Sclerodermataceae, Basidiomycota) and Quercus coccifera (Fagaceae, Angiospermae). Cryptogamie Mycologie 32, 95-102.

Dix NJ, Webster J. 1995 - Fungal Ecology. Chapman and Hall, London.

Edgar RC. 2004 - MUSCLE: multiple sequence alignment with high accuracy and high throughput. Nucleic Acids Research 32, 1792-1797.

Felsenstein J. 1985 - Confidence intervals on phylogenetics: an approach using bootstrap. Evolution 39, 783-791.

Gafur A, Schützendübel A, Langenfeld-Heyser R, Fritz E, Polle A. 2004 - Compatible and incompetent Paxillus involutus isolates for ectomycorrhiza formation in vitro with poplar (Populus canescens) differ in $\mathrm{H}_{2} \mathrm{O}_{2}$ production. Plant Biology 6, 91-99.

Gomes F, Machado H, Martin ES, Portugal A, Canhoto JM. 2013 - Mycorrhizal synthesis between Pisolithus arhizus and adult clones of Arbutus unedo in vitro and in nursery. Journal of Forestry Research 24, 659-670. 
Garay-Serrano E, Bandala VM, Montoya L. 2012 - Morphological and molecular identification of the ectomycorrhizal association of Lactarius fumosibrunneus and Fagus grandifolia var. mexicana trees in eastern Mexico. Mycorhiza 22, 583-588.

Guerin-Laguette A, Vaario LM, Gill WM, Lapeyrie F, Matsushita N, Suzuki K. 2000 - Rapid in vitro ectomycorrhizal infection on Pinus densiflora roots by Tricholoma matsutake. Mycoscience 41, 389-393.

Hung LL, Chien CY. 1979 - Two new mycorrhizal syntheses: Pisolithus tinctorius and Suillus bovinus with Taiwan red pine. Mycologia 71, 202-206.

Hung LL, Trappe JM. 1983 - Growth variation between and within species of ectomycorrhizal fungi in response to $\mathrm{pH}$ in vitro. Mycologia 75, 234-241.

Islam F, Ohga S. 2013 - Effects of media formulation on the growth and morphology of ectomycorrhizae and their association with host plant. International Scholarly Research Notices Agronomy, 1-12.

Kanchanaprayudh J, Zhou Z, Yomyart S, Sihanonth P, Hogetsu T. 2003a - Molecular phylogeny of ectomycorrhizal Pisolithus fungi associated with pine, dipterocarp, and eucalyptus trees in Thailand. Mycoscience 44, 287-294.

Kanchanaprayudh J, Zhou Z, Yomyart S, Sihanonth P et al. 2003b - A new species, Pisolithus abditus, an ectomycorrhizal fungus associated with dipterocarps in Thailand. Mycotaxon 88, 463-467.

Kumla J, Danell E, Bussaban B, Lumyong S. 2011 - Suitable growth conditions and nutrition factors on in vitro culture of Phlebopus portentosus (Boletales). Chiang Mai Journal of Science 38, 156-159.

Langer I, Krpata D, Peintner U, Wenzel WW, Schweiger P. 2008 - Media formulation influences in vitro ectomycorrhizal synthesis on the European aspen Populus tremula L. Mycorrhiza 18, 297-307.

Lee SS, Patahayah M, Chong WS, Lapeyrie F. 2008 - Successful ectomycorrhizal inoculation of two dipterocarp species with a locally isolated fungus in Peninsular Malaysia. Journal of Tropical Forest Science 20, 237-247.

Martin F, Díez J, Dell B, Delaruelle C. 2002 - Phylogeography of the ectomycorrhizal Pisolithus species as inferred from nuclear ribosomal DNA ITS sequences. New Phytologist 153, 345357.

Marx DH. 1977 - Tree host range and world distribution of the ectomycorrhizal fungus Pisolithus tinctorius. Canadian Journal of Botany 23, 217-223.

McLaughlin DJ. 1970 - Environmental control of fruitbody development in Boletus rubinellus in axenic culture. Mycologia 62, 307-331.

Molina R, Trappe JM. 1982 - Lack of mycorrhizal specificity by the Ericaceous hosts Arbutus menziesii and Arctostaphylos uva-ursi. New Phytologist 90, 495-509.

Paolocci F, Rubini A, Granetti B, Arcioni S. 1999 - Rapid molecular approach for a reliable identification of Tuber spp. ectomycorrhizae. FEMS Microbiology Ecology 28, 23-30.

Pereira OL, Costa MD, Borges AC, Araujo EF, Kasuya MCM. 2005 - Compatibility and ectomycorrhiza formation among Pisolithus isolates and Eucalyptus spp. Revista Brasileira de Ciência do Solo 29, 337-344.

Phosri C, Martin MP, Suwannasai N, Sihanonth P, Watling R. 2012 - Pisolithus: a new species from southeast Asia and a new combination. Mycotaxon 120, 195-208.

Pruett GE, Bruhn JN, Mihail JD. 2009 - Greenhouse production of burgundy truffle mycorrhizae on oak roots. New Forests 37, 43-52.

Ronquist F, Teslenko M, van derMark P, Ayres DL, Darling A, Höhna S, Larget B, Liu L, Suchard MA, Huelsenbeck JP. 2012 - MrBayes 3.2: efficient Bayesian phylogenetic inference and modelchoice across a large model space. Systematic Biology 61, 539-542.

Rossi MJ, Oliveira VL. 2011 - Growth of the ectomycorrhizal fungus Pisolithus microcarpus in different nutritional conditions. Brazilian Journal of Microbiology 42, 624-632. 
Sanchez F, Honrubia M, Torres P. 2001 - Effects of $\mathrm{pH}$, water stress and temperature on in vitro cultures of ectomycorrhizal fungi from Mediterranean forests. Cryptogamie Mycologie 22, 243-258.

Sanmee R, Lumyong P, Dell B, Lumyong S. 2010 - In vitro cultivation and fruit body formation of the black bolete, Phlebopus portentosus, a popular edible ectomycorrhizal fungus in Thailand. Mycoscience 51, 15-22.

Siri-in J, Kunla J, Suwannarach N, Lumyong S. 2014 - Culture condition and some properties of pure culture of ectomycorrhizal fungus, Scleroderma sinnamariense. Chiang Mai Journal of Science 41, 275-285.

Srinivasan M, Natarajan K, Nagarajan G. 2000 - Growth optimization of an ectomycorrhizal fungus with respect to $\mathrm{pH}$ and temperature in vitro, using design of experiment. Bioprocess Engineering 22, 267-273.

Swofford DL. 2002 - PAUP*: Phylogenetic analysis using parsimony (*and other methods), beta version 4.0b10. Sinauer Associates, Sunderland.

Tam PCF. 1994 - Mycorrhizal associations in Pinus massoniana Lamb. and Pinus elliottii Engel. inoculated with Pisolithus tinctorius. Mycorrhiza 4, 255-263.

Taylor AFS, Alexander I. 2005 - The ectomycorrhizal symbiosis: life in the real world. Mycologist $19,102-112$.

Thongklang N, Hyde KD, Bussaban B, Lumyong S. 2010 - Culture condition, inoculum production and host response of a wild mushroom, Phlebopus portentosus strain CMUHH121-005. Maejo International Journal of Science Technology 5, 413-425.

Turjaman M, Tamai Y, Segah H, Limin SH et al. 2005 - Inoculation with the ectomycorrhizal fungi Pisolithus arhizus and Scleroderma sp. improves early growth of Shorea pinanga nursery seedlings. New Forests 30, 67-73.

Vaario LM, Gill WM, Lapeyrie F, Matsushita N, Suzuki K. 2000 - Aseptic ectomycorrhizal synthesis between Abies firma and Cenococcum geophilum in artificial cuture. Mycoscience 41, 395-399.

Vaario LM, Tanaka M, Ide Y, Gill WM, Suzuki K. 1999 - In vitro ectomycorrhiza formation between Abies firma and Pisolithus tinctorius. Mycorrhiza 9, 177-183.

Watling R, Taylor A, See LS, Sims K, Alexander I. 1995 - A rain-forest Pisolithus: its taxomomy and ecology. Nova Hedwigia 61, 417-429.

White TJ, Bruns TD, Lee S, Taylaor JW. 1990 - Amplification and direct sequencing of fungal ribosomal RNA genes for phylogenetics. In: Innis MA, Gelfand DH, Sninsky JJ, White TJ (eds), PCR protocols: a guide to methods and applications. Academic, San Diego, pp 315322.

Wilson AW, Binder M, Hibbett DS. 2011 - Effect of gasteroid fruiting body morphology on diversification rate in three independent clades of fungi estimated using binary state speciation and extinction analysis. Evolution 65, 1305-1322.

Xu M, Zhu J, Kang H, Xu A, Zhang J, Li F. 2008 - Optimum conditions for pure culture of major ectomycorrhizal fungi obtained from Pinus sylvestris var. mongolica plantations in southeastern Keerqin sandy lands, China. Journal of Forestry Research 19, 113-118.

Yadav A, Yadav K. 2012 - Physiological study of two ectomycorrhizal fungi isolated from Kumaun Himalaya. The Indian Forester 138, 17-21.

Yamanaka T. 2003 - The effect of $\mathrm{pH}$ on the growth of saprotrophic and ectomycorrhizal ammonia fungi in vitro. Mycologia 95, 584-589.

Yamanaka T, Ota Y, KonnoM, Kawai M et al. 2014 - The host range of conifer-associatied Tricholoma matsutake, Fagaceae-assoviated T. bakamatsutake and T. fulvocasin vitrotaneum are wider in vitro than in nature. Mycologia 106, 397-406. 